\title{
Study of knowledge and willingness regarding eye donation among medical students of a tertiary care teaching hospital of central India
}

\author{
Rajesh Kumar Ahirwar*, Pallavi R. Shidhaye, Indu J. Ekka, D. M. Saxena
}

Department of Community Medicine, L. N. Medical College and Research Centre, Bhopal, Madhya Pradesh, India

Received: 13 July 2016

Accepted: 22 July 2016

*Correspondence:

Dr. Rajesh Kumar Ahirwar,

E-mail: dr.rajesh326@gmail.com

Copyright: (c) the author(s), publisher and licensee Medip Academy. This is an open-access article distributed under the terms of the Creative Commons Attribution Non-Commercial License, which permits unrestricted non-commercial use, distribution, and reproduction in any medium, provided the original work is properly cited.

\section{ABSTRACT}

Background: Corneal diseases constitute a significant cause of visual impairment and blindness in the developing world. Corneal blindness constitutes $1 \%$ of total blindness. Corneal ulcers have also been recognised as a major cause of blindness in developing countries. One of the obstacles in eye donation is lack of awareness and a negative attitude among general population. The willingness about eye donation among medical fraternity definitely will affect the attitude among general population. The present study was conducted to assess the knowledge and willingness about eye donation among medical students of a tertiary care teaching hospital of central India.

Methods: A cross-sectional study was carried out in the tertiary care teaching hospital in Bhopal during the period of September 2013 to October 2013. A total of 467 students were selected by convenient sampling. Pre-designed and pre-structured questionnaire was used for data collection. Data were entered in MS Excel sheet and analyzed by STATA-11.

Results: A total of 467 students, out of which 263 (56\%) were males and 204 (44\%) female students and $380(81.4 \%)$ were aware about eye donation. The knowledge regarding eye donation was found to be statistically significant with the gender of the participant ( $\mathrm{p}<0.001) .289(61.9 \%)$ students were willing to donate eyes, out of which $161(56 \%)$ were males and $128(44 \%)$ were females ( $\mathrm{p}=0.73)$. Among the participants, 97(37\%) males and $70(34 \%)$ females did not know about any existing eye bank in MP or India.

Conclusions: The present study revealed that most of the students were aware regarding eye donation and most of them were willing to donate their eyes. So continuous awareness programmes and camps should be held and should include not only the community population but also for the undergraduate medical students.

Keywords: Knowledge, Willingness, Eye donation, Medical students, Tertiary hospital

\section{INTRODUCTION}

Corneal diseases constitute a significant cause of visual impairment and blindness in the developing world. ${ }^{1}$ Corneal blindness constitutes $1 \%$ of total blindness. ${ }^{2}$ Corneal ulcers have also been recognised as a major cause of blindness in developing countries. ${ }^{3}$ As per the National Program for Control of Blindness (NPCB), prevalence of blindness is $1 \%$ in India. ${ }^{4}$ The Andhra Pradesh eye disease study (APEDS) reported the prevalence of corneal blindness at $0.13 \%$ constituting $9 \%$ of all blindness. ${ }^{5}$ Eye donation is an act of donating one's eyes after his/her death. Only corneal blinds can be benefitted through this process not other blinds. It is an act of charity, purely for the benefit of the society and is totally voluntary. ${ }^{6}$ Well informed medical students could be expected to influence the eye donation rates. ${ }^{7}$ One of the obstacles in eye donation is lack of awareness and a negative attitude among general population. The willingness about eye donation among medical fraternity definitely will affect the attitude among general 
population. There are many studies regarding awareness of eye donation among student groups like medical college students, nursing college students, etc. But still there is a huge demand supply gap regarding eye donation. There are many awareness programmes running in the country which shall definitely increase the willingness for eye donation. Keeping this in mind the present study was conducted to determine the awareness and associated demographic factors in relation to eye donation among medical students so that necessary intervention programmes can be executed during their academic sessions.

\section{METHODS}

A cross-sectional epidemiological study was carried out during the period of September 2013 to October 2013. The present study was conducted in the tertiary care teaching hospital in Bhopal, Central India. It has its own teaching institute catering to a population coming from all classes of society but predominantly from the middle and lower classes. Total 467 students from all the academic semesters of the medical college were selected for the study. All the students who gave consent were included in the study. Verbal consent was taken before including them in the study. Thus a total of 467 students were selected by convenient sampling. Pre-designed and pre-structured questionnaire was used to obtain basic socio-demographic information like age, gender, religion, education of the participants. Data collection was meticulously done by the post graduate student in the department of community medicine. Information related to awareness regarding eye donation, intention to donate eyes, reasons for donating or pledging and not, and sources of information was also collected. The students were explained about the scope of the study and later given the questionnaire after the teaching classes. Those who were willing to donate the eyes were informed about nearest eye bank. Information given by the participants and their identity were kept confidential. Data were judiciously entered in MS Excel sheet and analyzed by STATA 11. Tables, percentage and chi-square test was used for analysis of data.

\section{RESULTS}

It was seen from Table 1 that total 467 MBBS students participated in the study, out of which $263(56 \%)$ were males and 204 (44\%) female students. 253 (54.2\%) students belonged to age group 21-25 years and 214 $(45.8 \%)$ belonged to age group $15-20$ years. Highest number who volunteered to participate in the study were third year students $151(32.3 \%)$ followed by $129(27.6 \%)$ final year students.

Table 1: Distribution of study population according to socio-demographic characteristics $(\mathrm{n}=467)$.

\begin{tabular}{|c|c|c|c|c|c|}
\hline \multirow{2}{*}{ Variables } & \multicolumn{2}{|c|}{$\begin{array}{l}\text { Males } \\
(n=263)\end{array}$} & \multicolumn{2}{|c|}{ Females $(n=204)$} & \multirow{2}{*}{ Total } \\
\hline & No. & $\%$ & No. & $\%$ & \\
\hline \multicolumn{6}{|l|}{ Age (in years) } \\
\hline $15-20$ & 119 & 45 & 95 & 47 & $214(45.8)$ \\
\hline $21-25$ & 144 & 55 & 109 & 53 & $253(54.2)$ \\
\hline \multicolumn{6}{|l|}{ Education } \\
\hline First Year & 42 & 16 & 51 & 25 & $93(19.9)$ \\
\hline Second & 58 & 22 & 36 & 18 & $94(20.1)$ \\
\hline Third & 87 & 33 & 64 & 31 & $151(32.3)$ \\
\hline Fourth & 76 & 29 & 53 & 26 & $129(27.6)$ \\
\hline \multicolumn{6}{|c|}{ Socio- economic status } \\
\hline Upper (I) & 165 & 63 & 119 & 58 & $284(60.8)$ \\
\hline Upper middle (II) & 63 & 24 & 57 & 28 & $120(25.7)$ \\
\hline Lower middle (III) & 35 & 13 & 28 & 14 & $63(13.5)$ \\
\hline Upper lower (IV) & 0 & 0 & 0 & 0 & 0 \\
\hline Lower (V) & 0 & 0 & 0 & 0 & 0 \\
\hline \multicolumn{6}{|l|}{ Type of family } \\
\hline Nuclear & 126 & 48 & 87 & 43 & $213(45.6)$ \\
\hline Joint & 94 & 36 & 85 & 42 & $179(38.3)$ \\
\hline Three Generation & 43 & 16 & 32 & 15 & $75(16.1)$ \\
\hline \multicolumn{6}{|l|}{ Religion } \\
\hline Hindu & 198 & 75 & 147 & 72 & $345(73.9)$ \\
\hline Muslim & 11 & 4 & 18 & 9 & $29(6.3)$ \\
\hline Christian & 8 & 3 & 6 & 3 & $14(2.9)$ \\
\hline Others & 46 & 17 & 33 & 16 & $79(16.9)$ \\
\hline
\end{tabular}


Majority of the students belonged to upper class 284 $(60.8 \%)$ followed by upper middle class with 120 $(25.7 \%)$ students and $63(13.5 \%)$ students belonged to lower middle class. There were no students who belonged to lower socio-economic status. Most of the students were from nuclear families $213(45.6 \%)$ followed by 179
(38.3\%) from joint families and $75(16.1 \%)$ were from three generation families. Majority of the students were hindus $345(73.9 \%)$ followed by students from other religion $79(16.9 \%), 29(6.3 \%)$ were muslims and 14 (2.9\%) were christians.

Table 2: Distribution of study population according to knowledge and perceptions regarding eye donation among medical students $(n=467)$

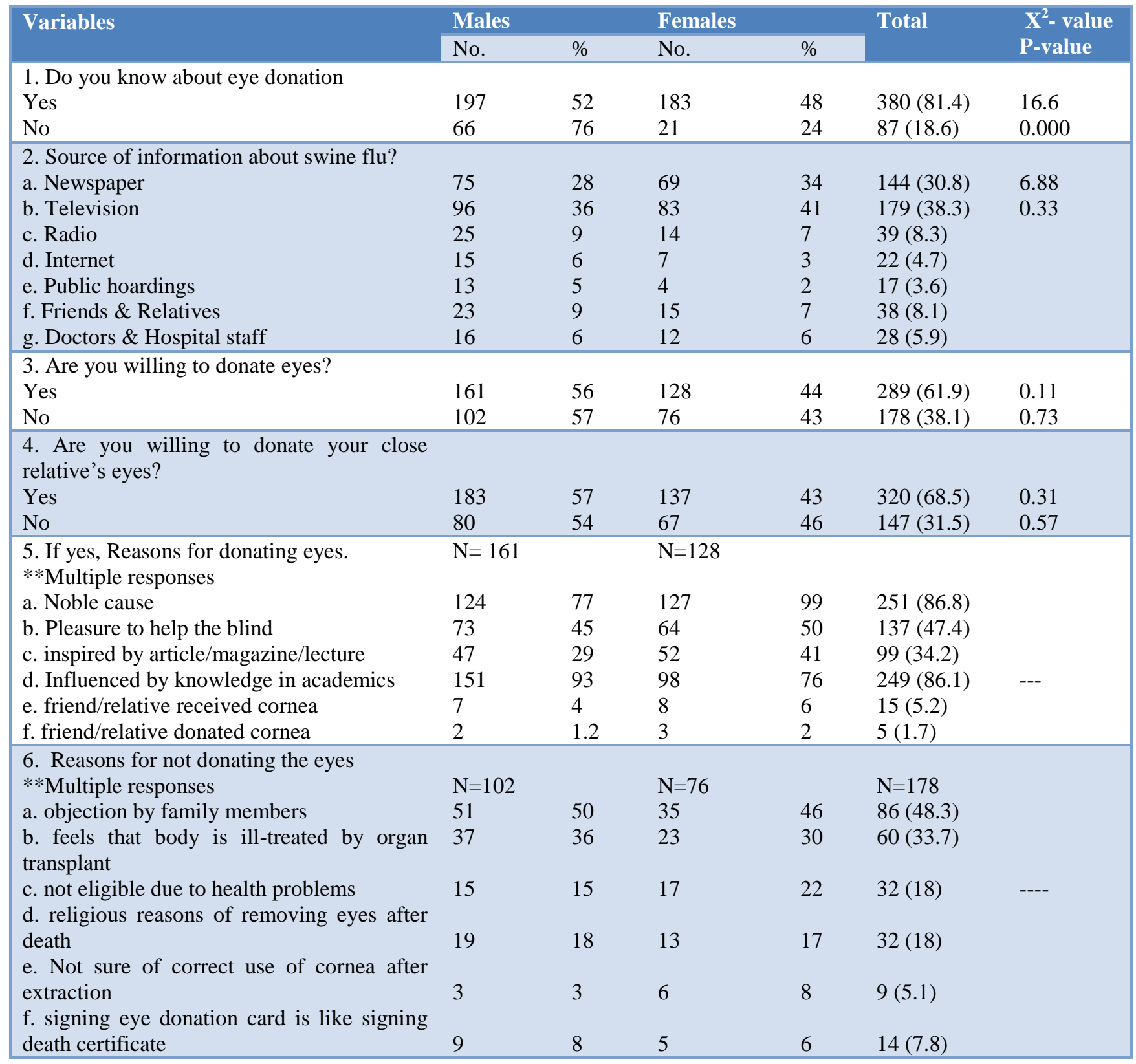

It is evident from Table 2, out of total 467 students, 380 $(81.4 \%)$ were aware about eye donation. But still 87 $(18.6 \%)$ were not aware of eye donation. Out of those who were aware, $197(52 \%)$ were males and $183(48 \%)$ were females. The knowledge regarding eye donation was found to be statistically significant with the gender of the participant $(\mathrm{p}<0.001)$. Maximum students, 179 (38.3) knew about eye donation through television followed by newspaper, radio or Internet. $17(3.6 \%)$ students knew from public hoardings. Very few 28 (5.9\%) came to know from doctors and hospital staff and academic classes. $289(61.9 \%)$ students were willing to donate eyes, out of which 161 (56\%) were males and 128 (44\%) 
were females $(p=0.73) .320(68.5 \%)$ students were willing to donate the eyes of close relatives $(p=0.57)$. The students were asked about the various reasons for donating eyes. Out of 289 students who were willing to donate eyes, $251(86.8 \%)$ students thought eye donation as a noble cause, $137(47.4 \%)$ felt pleasure in helping the blind, $99(34.2 \%)$ students were inspired by article/magazine/lecture. $249(86.1 \%)$ students told they were influenced by the knowledge they received during their academic classes. 178(38.1\%) students were not willing to donate the eyes. $86(48.3 \%)$ students didn't wish to donate eyes as they had objection from family members. $60(33.7 \%)$ students feel that body is ill-treated after death for eye donation. Very few students, 32 (18\%) had valid medical reasons for not donating the eyes. 14 (7.8\%) students felt that signing eye donation card was like signing death certificate.

Table 3: Distribution of study population according to knowledge regarding eye donation among medical students.

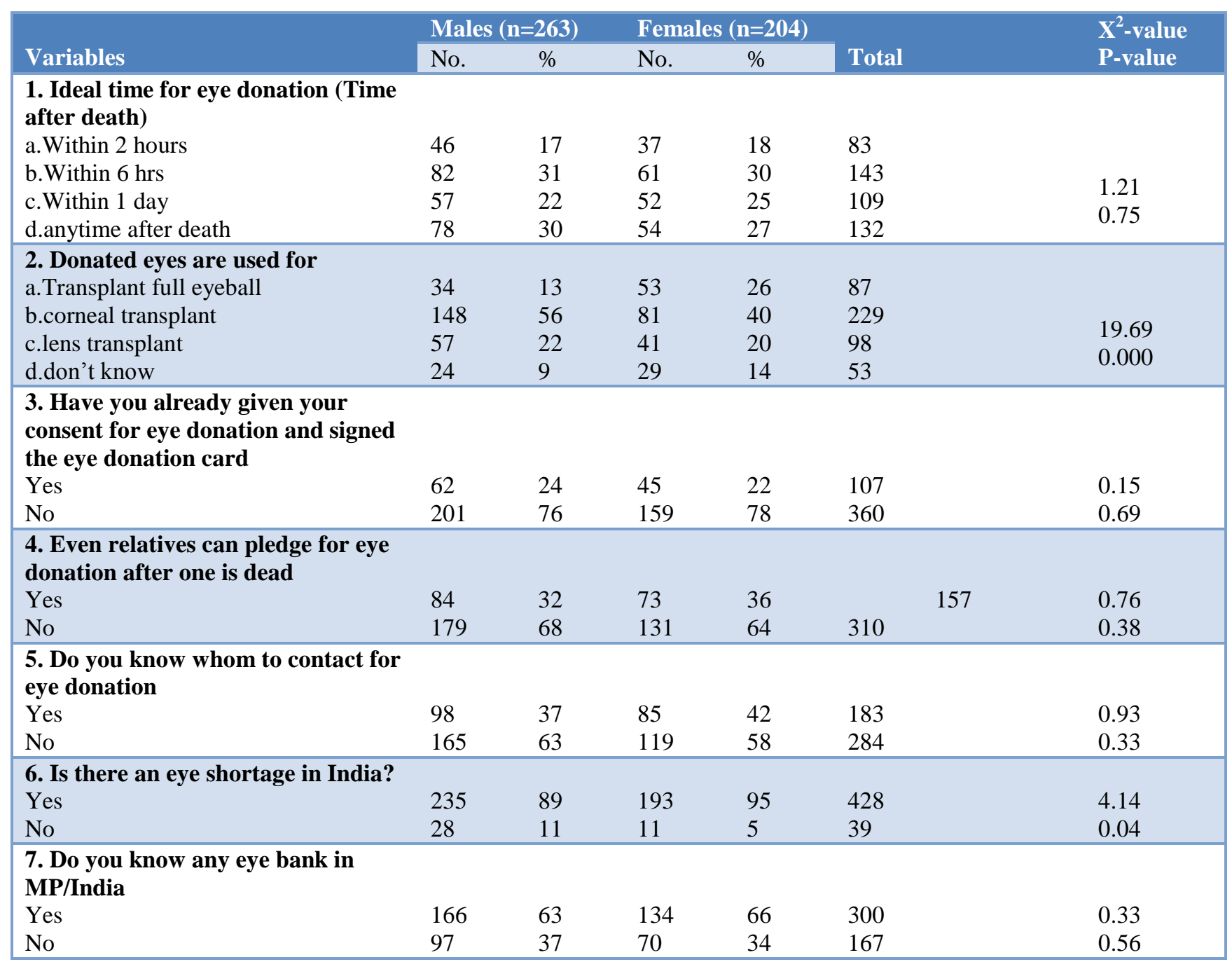

It was observed from Table 3, only $82(31 \%)$ males and $61(30 \%)$ females knew that eyes can be removed within 6 hours of death for effective use. 148 (56\%) males knew that cornea is used for grafting but among females only $81(40 \%)$ showed any awareness about the topic. Only 62 (24\%) males and $45(22 \%)$ females had given consent for eye donation and signed the eye donation card.

$179(68 \%)$ males and $131(64 \%)$ females did not know that even relatives can pledge for eye donation. 165 (63\%) males and 119 (58\%) females did not know whom to contact for eye donation. Majority 235 (89\%) males and $193(95 \%)$ females were aware about shortage of eye in India. Among the participants, 97 (37\%) males and 70 (34\%) females did not know about any existing eye bank in Madhya Pradesh or India.

\section{DISCUSSION}

Medical students are the potential part of the community who shall be the role models for the general population. There is a shortage of cornea among developing country 
like India and imbalance between demand-supply of cornea for transplant. Reviews have revealed lack of knowledge and negative attitude regarding organ donation amongst health professionals. ${ }^{8}$

In this study, out of total 467 students, 380 (81.4\%) were aware about eye donation. In a study by Priyadarshan B et al, among the south Indian population, $50.7 \%$ of participants were aware of eye donation. ${ }^{9}$ Singh MM et al found that $87.8 \%$ of the medical students were willing to be eye donors. ${ }^{10}$ Dhaliwal et al reported that $80 \%$ of the students were willing to donate eyes. ${ }^{11}$ A similar study which was conducted in Bhopal city showed that $98 \%$ of the total students had heard about eye donation previously, only $46 \%$ of them were willing to pledge their eyes for donation, and merely $22 \%$ of them were willing to donate their relatives' eyes. ${ }^{12}$ The present study showed that 179 (68\%) males and 131 (64\%) females did not know that even relatives can pledge for eye donation.

In this study, maximum students 179 (38.3) knew about eye donation through television followed by newspaper, radio or internet. Similar results were shown in the study done by Singh MM et al which showed $77.8 \%$ source by television. ${ }^{10}$ Tondon $\mathrm{R}$ et al and Giri PA et al showed that information by mass media were the main reason of awareness in $61.3 \%$ and $58.2 \%$ of students respectively. ${ }^{13,14}$

Knowledge regarding the number of hours after death within which eye should be removed for donation was poor $(39.7 \%)$ in study conducted by Kumar $S$ et al as compared to college students at Hubli. ${ }^{12,15}$ In our study, $97(37 \%)$ males and 70 (34\%) females did not know about any existing eye bank in MP or India. As against this, Nekar MS et al reported that $74 \%$ of the college students at Hubli knew about eye banks in their surroundings. ${ }^{15}$

In our study, we found that $289(61.9 \%)$ were willing to donate the eyes. Only $82(31 \%)$ males and $61(30 \%)$ females knew that eyes can be removed within 6 hours of death for effective use. It is a matter of concern that only $50 \%$ of the persons interviewed had knowledge of eye donation, $20 \%$ knew about corneal transplantation and only $4.34 \%$ of them knew when to donate their eyes. Singh $\mathrm{M}$ et al found that $61 \%$ of students knew correct time of eye donation. ${ }^{16}$

Our study showed that majority $235(89 \%)$ males and 193 (95\%) females were aware about shortage of eye in India. Among the participants, 97 (37\%) males and 70 (34\%) females did not know about any existing eye bank in MP or India. Singh MM et al in their study at Delhi showed that, only $49(27.2 \%)$ out of 180 students knew about appropriate place for eye donation. ${ }^{10}$ A study done on final year medical students in adult population of Southern India showed that $67.4 \%$ students could name a few eye banks.179 (68\%) males and 131 (64\%) females did not know that even relatives can pledge for eye donation. Similarly Kumar S et al found that majority of the students $(68 \%)$ feel that consent of the family members is necessary before pledging eyes in Bhopal. ${ }^{12}$

\section{CONCLUSION}

The present study concluded that the knowledge regarding eye donation among medical students was good but still few didn't know about the details related to the eye donation. So continuous awareness programmes and camps should be held and should include not only the community population but also for the undergraduate medical students. The present study revealed that most of the students were aware regarding eye donation and most of them were willing to donate their eyes. Those who were not willing to donate their eyes or their relatives eyes had very indifferent reasons which can be changed with health education regarding various myths and misconceptions among medical students and their families and general community.

National Blindness Control Programme is being implemented since many years but still medical students are unaware of the very basics of eye donation. It is thus to be seen that misconceptions persist not only in the general population but also among the medical students which can be easily dealt with during the course of medical education and rigorous health education. Studies are also required to identify existing barriers to eye donation. Medical students will act as role model in the noble cause of eye donation and thus shall help in reducing the demand supply gap for corneal transplants.

\section{ACKNOWLEDGEMENTS}

Authors express their sincere gratitude to all the students for sparing their time to participate in this study.

Funding: No funding sources

Conflict of interest: None declared

Ethical approval: The study was approved by the Institutional Ethics Committee

\section{REFERENCES}

1. Thylefors B, Negrel AD, Pararajasegaram R, Dadzie KY. Global data on blindness. Bull WHO. 1995;73:16-21.

2. Consolidated report for the eye donation centres under Nehru Drishti Yojna in Haryana for the year 2010. NPCB report 2010.

3. Whitcher JP, Srinivasan M. Corneal ulceration in the developing world - a silent epidemic. $\mathrm{Br} \mathrm{J}$ Ophthalmol. 1997;81:622-3.

4. Govt. of India, Annual Report 2013-2014, Ministry of Health and Family Welfare, New Delhi. 2014.

5. Dandona L, Dandona R, Srinivas M, Giridhar P, Vilas K, Prasad MN et al. Blindness in Indian state of Andhra Pradesh. Invest Ophthalmol Vis Sci. 2001;42:908-16. 
6. Mohan RK. Eye donation. Available at http://www.mohanfoundation.org. Accessed on 7th December 2015.

7. Kannan KA. Eye donation movement in India. J Indian Med Assoc 1999;97:318-9.

8. Jaini JS, Reddy MK, Jain AK, Ravinder MS, Jhaveria S, Raghuram L. Prespectiveness on eye banking. Indian J ophthalmol. 1996:44:47-55.

9. Priyadarshan B, Srinivasan M, Padmavathi A, Selvam R, Nirmalan. Awareness of eye donation in an adult population of southern India- a pilot study. Indian J Ophthalmol. 2003;51:101-4.

10. Singh MM, Rahi M, Pagare D, Ingle GK. Medical student's perception on eye donation in Delhi. Indian J Ophthalmol. 2007;55(1):49-53.

11. Dhaliwal U. Enhancing eye donation rates training students to be motivators. Indian J Ophthalmol. 2002;50:209-12.

12. Kumar S, Shukla US, Prakash, Agarwal P. Awareness and knowledge on eye donation among students at Bhopal. Natl J Community Med. 2012;3(4):685-89.
13. Tondon R, Verma K, Vanathy M, Pandey RM, Bajpayee RB. Factors affecting eye donation from post-mortem cases in a tertiary care hospital. Cornea. 2004;23(6):597-601.

14. Giri PA, Phalke DB, Phalke VD. Awareness and perception about eye donation amongst interns of Rural Medical College Loni, Maharashtra. Indian Medical Gazette. 2010;CXLIV(1):36-38.

15. Nekar MS, Lokare L, Gokhale SA, Godbole M, Mulkipatil SY. Awareness of eye donation among college students of Hubli city, Karnataka. Int J Biomed Res. 2012;3(4):201-4.

16. Singh M, Bharadwaj A, Ahliwalia SK, Saini S, Qadri S. Eye donation: perception and promoting factors among medical students. Indian $\mathbf{J}$ Community Health. 2012;3(24):175-8.

Cite this article as: Ahirwar RK, Shidhaye PR, Ekka IJ, Saxena DM. Study of knowledge and willingness regarding eye donation among medical students of a tertiary care teaching hospital of central India. Int J Community Med Public Health 2016;3:2363-8. 